\title{
1. The context for observation
}

\section{John Taylor}

This monograph explores some of the problems, successes and policy issues related to the application of the Indigenous Enumeration Strategy (IES) in the enumeration of Aboriginal people in remote parts of Australia. It is based on the evidence of direct observations made by three researchers from the Centre for Aboriginal Economic Policy Research (CAEPR) of the conduct of the 2001 Census enumeration in three separate localities. The localitiesa major Aboriginal township, an outstation, and a series of urban town camps-were deliberately selected to be broadly representative of Indigenous settlement patterns across the remote north and centre. The aim was to sample a range of residential settings in the event that this variation had any bearing on the conduct and outcomes of the census. Access to the enumeration process was facilitated under the terms and conditions of confidentiality as specified by the Census and Statistics Act 1905. Each researcher was a signatory, thereby assuming official census 'observer' status.

Prior to the 1971 Census, relatively few resources were applied to the enumeration of Indigenous people resident in isolated localities, and the focus was very much on achieving a head count rather than a detailed profile of individual social and economic characteristics. Since that time, special census field procedures have been progressively devised, modified and extended by the Australian Bureau of Statistics (ABS) in an attempt to ensure as comprehensive coverage as possible of remote area populations, albeit within budgetary constraints. The direct cost of enumerating remote area Indigenous populations in 2001 was around $\$ 2$ million (or $\$ 26$ per head of population) compared with the direct cost of around $\$ 49$ million (roughly $\$ 2.60$ per head) for the total population. This cost excludes a number of associated costs such as form printing and transport, the processing of forms and the preparation of outputs (pers. comm. Paul Williams, ABS).

There are difficulties, however, in determining how effectively these monies are deployed in the pursuit of an optimal count and responses of good quality. The normal method of checking for accuracy in the count, using the post-enumeration survey, is not applied to the remote area Indigenous population. There is no standard test for the quality of the data on population characteristics, short of editing rules that might be applied at the data processing stage.

In remote Aboriginal communities, then, there is a need for close scrutiny of census procedures to assess whether existing methods produce optimal results, or whether alternative or refined methods are needed. These assessments, in turn, have resource implications of interest beyond the confines of ABS operational systems. For example, the Aboriginal and Torres Strait Islander Commission (ATSIC) considers that both planning and policy formulation begin with demographic facts. Indeed, the broad parameters of ATSIC's charter are determined by the size, growth, composition and changing location of the Indigenous population. These factors also provide the basis for assessing issues of social justice such as the recognition of need and the fair and equitable distribution of resources (Menham 1992: 37). 
The ABS has claimed at times, on the basis of its own qualitative assessment, that the enumeration of remote area Indigenous populations may actually produce an overcount (ABS 1993: 6), yet analysts and other users of remote area census data have often asserted that the enumeration sometimes underestimates the numbers of Indigenous people. One particularly forceful claim, reported as part of a joint initiative of the Queensland and Commonwealth governments in the form of the Cape York Peninsula Land Use Strategy (CYPLUS), was that Indigenous people in Cape York Peninsula were substantially undercounted in 1991 (King 1994). However, this assertion was based on an invalid comparison between data from the 1991 ABS Census de facto counts of the Cape York population, and estimates of the 1994 place of usual residence (de jure) population derived from a variety of key informants in Cape York communities. To use the author's own assessment, it was constructed from deductive guesswork based on questionable assumptions (King 1994: 27-8). Such assertions of underenumeration provide no statistical basis for testing the proposition and serve only to obscure the likely underlying causes. Indeed, the validity of such contrary claims is difficult, if not impossible, to establish in the absence of demographic data that are directly comparable to those collected by the census.

It has also been claimed that the nature of census questions and the respondents' interpretations of them may misrepresent personal characteristics and patterns of social and economic organisation in remote Aboriginal communities (Ellanna et. al. 1988: 193-7; Commonwealth of Australia 1992; Jonas 1992; Martin \& Taylor 1996; Smith 1992). Misrepresentation of social and economic characteristics can occur because the concepts underpinning the census questions lack cross-cultural fit. Data on income provide a good example. The census measure of income applied in remote Indigenous communities refers to a period of time - a typical fortnight - whereas the flow of income to individuals and households in remote Indigenous communities is often intermittent. It is difficult to determine what might constitute usual fortnightly income in many Aboriginal households. Intermittent employment and windfall gains from sources such as gambling, cash loans and royalty payments, combined with debits, for example due to loss of employment and cash transfers to others, create a highly complex picture even over a short space of timeone that census methods of data gathering are likely to misrepresent (Smith 1991).

Attempts to describe household composition provide another example. In census terms, a household is defined as a group of two or more persons, who usually reside in the same dwelling, who regard themselves as a household, and who make common provision for food or other essentials for living. Visitors to the household are not included. Ethnographic evidence suggests that these are highly problematic definitions when applied to Aboriginal households, particularly in remote areas.

While there is some utility in confining the notion of a household to residents of a physical dwelling or location, Aboriginal households are typically highly fluid in composition, often with a more or less stable core of residents and a variable periphery of transient residents drawn from the same community or regional population pool. In such circumstances, it is clear that co-residential groupings (even in the limited sense of who sleeps where), commensal units, family groupings, and domestic economic units are not necessarily coterminous; for example, people who live together may not eat together. 
Commonly too, the basic economic and social units of Aboriginal societies comprise linked rather than single households (Altman 1987; Finlayson 1991; Henry \& Daly 2001; Martin \& Taylor 1996; Smith 1991, 1992), and what Aboriginal people themselves refer to as 'families' are typically dispersed across a number of households. It is such clusters of households, rather than individual households, which commonly form the basic units of sociality and consumption in remote Aboriginal communities.

The accuracy of census counts and of data on population characteristics, cannot adequately be established without reference to the particular circumstances of census-taking in remote Aboriginal communities. To date, a basic problem with the interpretation of census results has been the absence of well documented and fully nuanced accounts of this encounter between communities and officialdom.

There are some precedents for independent scrutiny of ABS field procedures. In 1981, two academics were invited to observe and report on preparations for the census count of remote Aboriginal communities in the Northern Territory (Loveday \& Wade-Marshall 1985). This exercise focused on three aspects of these preparations: the organisation of field procedures and training of collectors, the pre-census publicity campaign, and issues likely to arise from the administration of census forms and questions. All information was gleaned from meetings convened by Census Field Officers (CFOs). The actual count was not observed.

While scrutiny of the preparations for the 2001 remote Indigenous census count also formed part of the present exercise, the intention was much more to focus on the conduct of the count at the community level, as well as on the process of house to house interviewing. The framework, then, is a critical assessment of the application of western census-taking methods in a cross-cultural context. Loveday and Wade-Marshall (1985: 249) found that preparations for the 1981 Census threw into sharp relief the difficulties encountered by the ABS in translating census questions into the context of Aboriginal society in various kinds of settlement and in remote outstation locations. For the 2001 Census, the ABS has acknowledged a need for feedback on census field operations, as well as a desire to be more informed about the social and cultural contexts in which their efforts are expended. This has been some time in coming, although as with all shifts in administrative process, it has an essential history.

\section{Out of sight, out of mind: remote census counts before 1971}

In many aspects of Indigenous Australian life prior to the 1970s, exclusion from mainstream institutions was the order of the day. In the case of the census, this was built on the 1901 Constitution, which at s. 127 stated that in reckoning the numbers of the people of the Commonwealth, or of a State or other part of the Commonwealth, Aboriginal natives shall not be counted'. Within this constitutional provision, Aboriginal people were counted, only to be then excluded from reckoning, although in the early years there was not even an attempt at full enumeration of Aboriginal people prior to their exclusion. The Statistician's report on the 1911 Census set the tone: 
the full blooded Australian aboriginals...represent only those who were in the employ of whites at the date of the Census or were living in a civilised or semi-civilised condition in the vicinity of settlements of whites at that date. An enumeration of aboriginals living in a purely wild state was not undertaken (cited in Smith 1980: 30),

and

[f]rom time to time attempts have been made to ascertain the number of aboriginals in the various divisions of Australia, but the results have not been satisfactory, and the efforts in this direction of the Commonwealth Bureau of Census and Statistics at the taking of the Censuses in 1911 and again in 1921 proved disappointing (Commonwealth Bureau of Census and Statistics 1924: 951).

This comment on the 1921 Census is interesting: it was this census that saw the adoption of special methods designed to move towards more comprehensive and reliable population figures. This involved the cooperation of the Statisticians and Protectors of Aborigines in the States and the Northern Territory to arrive at an estimate of the total number of Aboriginal people, and their 'caste' and sex by administrative area (Smith 1980: 35). A system of annual Aboriginal censuses administered by welfare authorities was in place between 1921 and 1944, and it was claimed from 1933 onwards that coverage of the Indigenous population progressively improved with each succeeding census. In effect, though, for much of the twentieth century, the enumeration of remote Indigenous populations was more a case of mustering those administered by welfare authorities. As Smith (1980: 35) puts it, the 'practical difficulties' of enumeration were partly solved by the gradual movement of Aboriginal people into settlements - a process that was virtually complete by 1966 when the Bureau of Census and Statistics felt that, in conjunction with the Aboriginal welfare authorities, it had obtained for the first time a relatively complete enumeration of the Aboriginal population throughout Australia.

Thus, population counts essentially referred to individuals who were known to, and in regular contact with, welfare authorities. Numbers were presented by 'contact groups': those in contact with government settlements and depots, those in contact with missions, and those not in contact. This last group was classified as 'nomadic' and its numbers simply guesstimated. At the 1954 Census, for example, it was estimated that some 13,000 Aboriginal people were not contacted by census collectors (Commonwealth Bureau of Census and Statistics 1971: 7). By 1961, this figure was reduced to 4,000 and, as noted, the official view was that the 1966 Census was all-encompassing.

\section{The referendum of 1967 and beyond}

A census question relating to each person's 'origin' has been included in every Australian census since Federation, although the wording and format of this question have varied substantially since 1911 (Ross 1999). Before 1971, the origin question was structured in such a way as to ascertain each person's racial ' $\mathrm{mix}^{\prime}$. One reason for this was to exclude Aboriginal people (defined as those of greater than half Aboriginal descent) from the final count, as required by s. 127 of the Constitution. 
The repeal of s. 127 of the Constitution following the referendum of 1967 was pivotal in the subsequent history of census taking. It was no longer necessary, for the constitutional purposes of reckoning the 'numbers of people of the Commonwealth', to identify and exclude Aborigines. However, as the 1967 referendum also had the effect of bestowing responsibility on the Commonwealth for (in Constitutional terminology) the 'good government' of Indigenous people nationally, it also provided a basis, or a demand, for the establishment of systems to gather statistics on the Indigenous population in an inclusive, comprehensive and consistent manner. Thus, the Commonwealth Statistician reported in 1973 that:

For general interest, and in particular to meet the statistical requirements of Commonwealth and State authorities responsible for Aboriginal Affairs, it was decided that in the 1971 Census an attempt should be made to ascertain the race with which a person identifies himself (Commonwealth Bureau of Census and Statistics 1973: xiii).

\section{The development of special enumeration procedures}

In order to meet the new requirement for statistical data on Aboriginal Australians, the ABS introduced special arrangements for the 1971 Census in the Northern Territory and Western Australia. Over time, the system has been gradually modified and geographically extended and it now constitutes a multi-faceted Indigenous Enumeration Strategy (IES) that is an integral part of the general census operation. In urban areas, this strategy addresses issues arising from distrust of officials, population mobility and large households; in remote areas it is designed to take into account geographic isolation, high mobility, traditional culture, communication problems due to language, and unfamiliarity with form-filling. The focus of the present analysis is on the strategy as applied in remote areas.

Choi and Gray (1985) provide a history and evaluation of the initial steps taken by the ABS in its attempt to improve the enumeration of Indigenous people in remote areas at the 1971, 1976 and 1981 Censuses. Much of what they report is paraphrased here. They note that attempts to improve the coverage of Indigenous people in isolated situations (those 'out of contact') can be traced to the 1966 Census with the recruitment of Aboriginal welfare bodies, mission superintendents, station owners, patrol officers and police to assist in the count. However, they consider the outcome to have been less than satisfactory. Knowledge of the location of many Aboriginal people was lacking, too few people were allocated to undertake the count, and the personnel chosen were inappropriate because of general distrust of authority (Choi \& Gray 1985: 5).

By 1971, the new requirement to provide comprehensive data on the Indigenous population led to the development of dedicated procedures for application in the Northern Territory and Western Australia. For example, collection districts (CDs) were created for the first time in remote areas to cover most missions and government settlements, as well as certain pastoral properties known to contain concentrations of Aboriginal people. In the latter case, letters were sent to station owners, through the offices of pastoralists' associations, informing the owners about the census and requesting cooperation. Where possible, collectors were recruited from station staff, while Northern Territory patrol 
officers and Western Australian Native Welfare officers were also enlisted (Choi \& Gray 1985: 6). Some provision was also made for the first time to deal with enumeration problems among itinerant Indigenous populations in urban areas, although only in Darwin and Alice Springs. Logistical difficulties in conducting a simultaneous count over vast areas were addressed by commencing a population list one month prior to the census and adjusting for additions and departures at census date. Not surprisingly, this was found to be more effective in former mission and government settlements than in large reserves with indeterminate populations.

In the lead-up to the 1976 Census, the Department of Aboriginal Affairs (DAA) had been created, and responsibility for the census count of Indigenous people was centralised at the ABS in Canberra. As part of its expanding need for reliable population data, the DAA collaborated with the ABS in the design of special enumeration procedures for Indigenous people in town camps and remote communities, and input from the National Aboriginal Consultative Council (NACC) and other Aboriginal organisations was sought. Among the initiatives adopted were the use of Aboriginal census collectors in town camps, and the development of a special simplified questionnaire for communities where communication and literacy problems were identified. Flexibility in the timing of the count was also allowed in some Northern Territory communities in an attempt to accommodate significant movements of population.

Following a round of consultations with Aboriginal organisations and visits to major Aboriginal communities, the review of 1976 procedures recommended two significant changes for the 1981 enumeration that still resonate. The first involved the development of a special census schedule for use in interviewing individuals for whom English was a second or third language. The other was the devolving of central control of field procedures to the States and Territories, to take account of local conditions and to raise local awareness of the census. Over time this has led to some disparities in the implementation of the census methodology across jurisdictions, with the count being conducted sometimes on a place of enumeration (de facto) and sometimes on a place of usual residence (de jure) basis, and with individuals being recorded in a manner sometimes dictated more by expediency than by rigid adherence to the official methodology (Taylor 1993).

Enumeration by interview was pioneered in the Northern Territory at the 1976 Census and was extended to South Australia and Western Australia in 1981 (Queensland did not follow suit until 1991). In each of these jurisdictions, special CFOs were appointed to recruit and train collectors in Aboriginal communities, to promote pre-census publicity, and to physically locate communities (including outstations) to ensure their inclusion. In the Northern Territory the old system of relying heavily on police and other authorities for census collection was abandoned and a decision was made to recruit local Aboriginal people as interviewer-collectors in all discrete communities, with assistance in the major communities from adult educators (Loveday \& Wade-Marshall 1985). A modification of the standard household census form was also introduced. It was broken down into separate components: a household form listing household members along with information pertaining to the household, and a personal form for recording the socioeconomic characteristics of each individual within the household. Information on these forms was acquired by interviewing a responsible adult member of each household. A Dwelling Check List form was also developed for use at the community level. 
The benefit of devolving the jurisdiction of field operations is described by Loveday and Wade-Marshall (1985: 253) as enabling administrative flexibility resulting (in their estimation) in minimal underenumeration. Such flexibility included the production and distribution of customised pre-census publicity materials, the use of administrative records to fill information gaps, and return visits to communities where necessary.

\section{Current practice}

Subsequent development of the enumeration strategy in remote areas has essentially modified and extended the practices set in place in the Northern Territory, Western Australia and South Australia by 1981. Thus, the key operational features that set the remote area IES apart from the general census remain the use of interviewers and the administration of different forms with a modified format. While a systematic approach to interviewing and form-filling is outlined and encouraged in pre-census training, an ethos of local control and flexibility regarding just how the necessary information is to be acquired is also instilled. This can create additional idiosyncractic departures from general census practice.

The basic procedural structure of the IES is still as illustrated in Fig. 1.1, which shows the procedure for the 1991 Census. Using a Dwelling Check List (equivalent to the Community list in Fig. 1.1; see Appendix A for the 2001 Dwelling Check List), the first task of community coordinators (CCs) is to compile a comprehensive pre-enumeration listing of all dwellings in their community and to label each of these with a family name. Ideally, an estimate of the overall numbers of males and females assumed to be resident in each dwelling and available for interview should also be indicated. This process commences as soon as CFOs can organise and train an appropriate individual in each centre to do the job. Cross-checking of community lists with housing and other administrative lists is also encouraged. The method of compiling lists of dwellings and families may also vary according to who is involved, although this is generally done with assistance from council officials and other community record keepers.

Once constructed, the Dwelling Check Lists provide the basis for completing Special Indigenous Household Forms (SIHFs; see Appendix B for the 2001 SIHF), with one form for each household group (step 2; the SIHF corresponds to the Remote area household form of Fig. 1.1). In turn, Special Indigenous Personal Forms (SIPFs; see Appendix C for the 2001 SIPF) are completed (step 3; the SIPF corresponds to the Remote area personal form in Fig. 1.1) to record the personal details of each household member identified in step 2. The last two steps are, in theory at least, carried out by locally recruited interviewers in an interview with an identified household head - in effect an adult person with authority to provide information on behalf of all household members. In practice, the information may be supplemented from second-hand sources such as key informants and administrative records.

The process of administering each of these procedural steps inevitably involves a time lag with potential (and ultimately unknown) consequences for the accuracy of the count in terms of overlaps and omissions, especially in view of the high level of intra-regional population mobility in many areas. In recognition of this, fairly drastic measures are sometimes devised. In Yuendumu, for example, census day is brought forward by two weeks in those census years in which the real date coincides with the Yuendumu Sports Festival. This event draws large numbers of people into Yuendumu from all over central Australia (Young \& Doohan 1989: 192-7). 
Fig. 1.1 Procedural structure of the Indigenous Enumeration Strategy, 1991 Census

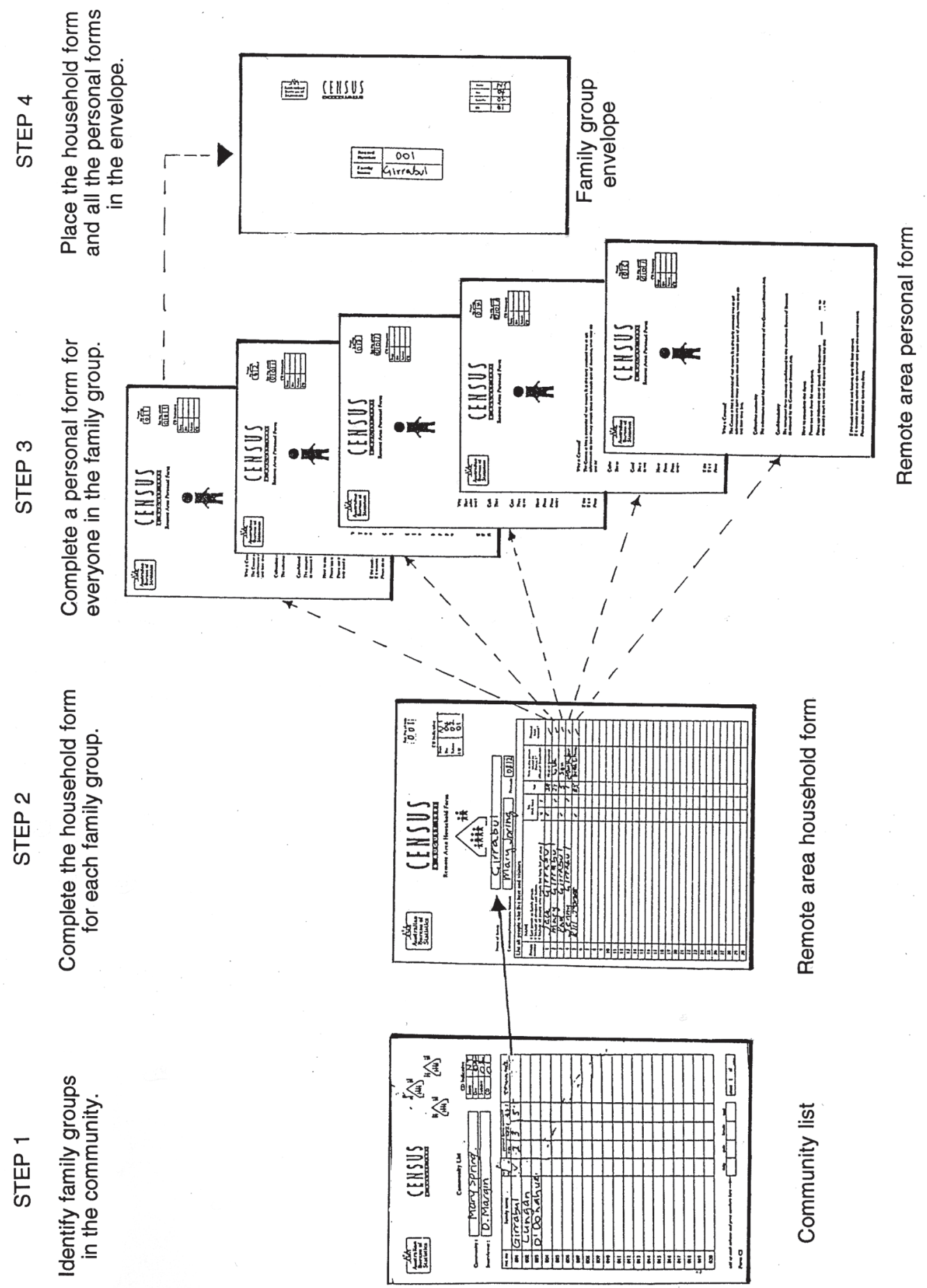




\section{Data quality}

The accuracy and reliability of census data is dependent on success in these and other staged procedures - in the wording of census questions, in the design of census questionnaires, in field procedures for administering questionnaires, in the level of respondent acceptance of the census, in the nature of the responses to the questions, and in the efficacy of the processes for translating census information to appropriate and meaningful data categories. For each of these procedures, issues and nuances arise that may potentially compromise data content and quality in the final analysis. For a variety of social, cultural, economic, political, administrative, and geographic reasons, this potential is heightened in the enumeration of Indigenous Australians.

The criticism that official statistics inadequately represent Indigenous numbers usually makes reference to an undercount (Commonwealth of Australia 1992), but may also refer to an overcount, as in the case of Tasmania, for example (ATSIC Tasmania 2000: 3). Whatever claims are made about census coverage, there is no escaping the fact that the official ABS estimate of a 7 per cent Indigenous census undercount in 1996 was substantially higher than the figure of 1.5 per cent calculated for the rest of the population (ABS 1998: 28), and this was true again in 2001 (6.5\% compared to 2.2\%; ABS 2002: 4). While this undercount is compensated for in ABS Indigenous population estimates at the Statistical Local Area level, the ABS cannot make adjustments at the more local level of Indigenous Locations where data error is most starkly exposed. At the 2001 Census, a total of 62,884 Indigenous people, or 17.8 per cent of the total, were counted using the SIPF: the potential implications of any undercount (or overcount) that might arise from these special procedures are not insignificant.

There appears to be little doubt that difficulties in accurately enumerating some remote Aboriginal populations have persisted. The ABS acknowledges that enumeration procedures failed in particular localities in 1996, such as in the Anangu Pitjantjatjara Lands (Ross 1999: 62-4), and wider problems are suggested by often erratic community and regional trends in intercensal population change that may reflect census or respondent error from one enumeration to another (Taylor 1997). Specific insight into the possible nature of such errors is provided by a case-study example of the 1996 enumeration in Kakadu National Park (Taylor 1999). While it is true that variation in counts from one census to another may simply reflect the changing de facto population on census night, the Kakadu study found similar variation in place of usual residence (de jure) figures which one would expect to display greater stability over time.

Only one known study has approached a rigorous validation of remote Indigenous census counts (Martin \& Taylor 1995, 1996). This concluded that there were systematic methodological flaws in the manner in which household membership was constructed using the Dwelling Check Lists and SIHFs. The result was an underenumeration, particularly of the young, the more mobile and the more socially marginal. Using ethnographic techniques to derive a separate and simultaneous count, this study estimated a census undercount of 17 per cent in the Cape York Peninsula community of Aurukun. While there is no basis for asserting that discrepancies of a similar magnitude exist elsewhere, the under-representation of such cohorts in official census counts is something 
that has long been noted by researchers (Gray \& Tesfaghiorghis 1993: 84) and is routinely acknowledged by the ABS (ABS 1993: 16-17, 1998: 28; Benham \& Howe 1994: 3), although no suggestions are put forward about why this might occur.

\section{Departures from standard procedures}

Clearly, enumeration of any kind in remote areas is a difficult task. Compounding the problems presented by dispersed settlement over large distances is the high mobility of the Aboriginal population in such areas. Furthermore, the geographical and social distribution of households and their individual members present definitional problems (Henry \& Daly 2001; Smith 2000a). The obstacles presented to accurate enumeration by these and other factors help to explain the gap that is sometimes observed between official and unofficial population counts, and between the statistical construction of social forms and the reality on the ground. Such conundrums would be resolved to some extent if documentation were available detailing the method and practice of enumeration. At the very least, those using data would be more aware of how they were acquired, thereby allowing greater precision in their interpretation. There are several unique features of the remote IES that have potential bearing on the quality of census output and of which users need to be appraised. These provided a focus of attention for the field observations of CAEPR researchers.

For pragmatic reasons - the fact of high intra-regional and intra-community mobility - two of the most fundamental features of standard census procedure in Australia are effectively overridden by the remote area strategy. In the standard enumeration as applied to the general population, a self-administered count occurs on a single day - census day (7 August in 2001). In contrast, while referring to the same census day, the process of remote area counting can begin weeks before the day itself and continue for some time after.

The second departure from normal enumeration procedures concerns the nature of the count. The Australian census is, in the first instance, a place of enumeration, or de facto count. There is some indication, however, that the Northern Territory office of the ABS encourages a place of usual residence, or de jure count. At the same time it seems likely that a mix of de jure and de facto counting may occur in all jurisdictions since individuals are recorded in a manner often dictated by expediency. A complicating factor is the question of who constitutes a visitor to a household and whether CFOs and CCs make assessments on this matter in a sufficiently coordinated way.

Another departure from standard census practice is the use of interviewers and specially designed forms and questions. While it was not possible for each researcher to fully observe the training of census collectors, observation of their interactions with respondents revealed much about its effectiveness. Direct observation also provided insight into respondent attitudes to census-taking as well as a host of related issues. These include problems posed in acquiring the personal details of household members in often very public situations, misunderstandings about the nature and meaning of certain questions, the struggle to translate Aboriginal conceptions of the social and economic world into those demanded by the questionnaire, and interviewing difficulties presented by the ordering of some questions and the length of time taken to interview. In observing these 
difficulties, particular attention was paid to any trade-offs that might occur between an ability to achieve the fundamental purpose of the census, that of securing accurate basic demographic information, and the increasingly burdensome task of detailing social and economic characteristics.

The costs and benefits of devolving control of field procedures and decision-making to local units was also under scrutiny. Census-taking in remote communities presents a logistical task of considerable proportions, and very often this demands approaches that can best be described as innovative, or at least individualistic. In observing the playing out of these strategies, it was possible to assess the degree to which flexibility in an otherwise highly structured system either enables or enhances enumeration. Also highlighted are the sorts of obstacles that collectors face. One issue that these observations illuminate is whether consistency applies across the count, either as a de facto or as a de jure enumeration. The intent of the ABS, centrally, is that it should be the former.

The three independent case studies that follow collectively shed light on the issues outlined above. In each case, a common methodology was applied involving (where possible) observation of training sessions for ABS staff and interviewers, 'over the shoulder' observation of actual census interviews, structured interviews with CFOs, CCs, and census interviewers (and officials of community councils where appropriate), observation of interactions between interviewers, CFOs and CCs, and observation of the organisation and administration of census logistics. While styles of inquiry and reporting vary, reflecting different disciplinary backgrounds (Martin and Morphy in anthropology, and Sanders in political science), the studies complement one another to present a holistic picture. It is interesting to note that a high degree of similarity is observed across quite separate geographic settings both in the range of practical issues faced by census collectors in pursuing their task, and in the responses of Aboriginal people to the exercise. These common findings, together with local nuances, are summarised in a final chapter with a view to considering future options for improving the census in remote Indigenous communities. 